\title{
Phytochemical Profiling of Ruta graveolens L. a Vital Medicinal Plant Using Gas Chromatography-Mass Spectrometry
}

\author{
Malik Aabid Hussain ${ }^{1 *}$, Varsha Nitin Nathar ${ }^{2}$ \\ ${ }^{1}$ Research Scholar, Department of Botany, Sant Gadge Baba Amravati University, Amravati, Maharashtra, India \\ 2Professor, Department of Botany, Sant Gadge Baba Amravati University, Amravati, Maharashtra, India
}

*Address for Correspondence: Mr. Malik Aabid Hussain, Department of Botany, Sant Gadge Baba Amravati University, Amravati, Maharashtra, India

E-mail: maabid1990@gmail.com

Received: 23 Jan 2020/ Revised: 17 Mar 2020/ Accepted: 27 Apr 2020

\begin{abstract}
Background: Ruta graveolens is a small evergreen sub-shrub of the family Rutaceae, 2-3 feet tall and almost as wide. It contains a mixture of alkaloids, coumarins, flavonoids, acridone alkaloids, essential oils etc. having various biological activities. The present study was designed to determine the volatile compounds present in various extracts of $R$. graveolens L. (Rue) using gas chromatography-mass spectrometry (GC-MS).

Methods: The leaves, stem and roots of $R$. graveolens were extracted using solvents like petroleum ether and chloroform by using Soxhlet apparatus for 24 hours and the extracts were analyzed through GC-MS. The mass spectra of the compounds observed were matched by the National Institute of Standards and Technology (NIST) library.

Results: The results revealed the presence of 1,4 and 6 chemical compounds in chloroform extracts of leaves, stem and roots, respectively, while as 1, 5, and 3 chemical constituents were identified in petroleum ether extracts of leaves, stem and roots respectively.

Conclusion: The study is a base to understand the richness of bioactive components in different extracts of $R$. graveolens L. Their isolation would have potential applications in drug designing as well as in the medical and healthcare industries.
\end{abstract}

Key-words: Gas Chromatography-mass spectrometry (GC-MS), Phytoconstituents, Ruta graveolens, Rutaceae, Volatile compounds

\section{INTRODUCTION}

Plants play an important role in the prevention and treatment of diseases and can minimize the side effects of conventional treatments ${ }^{[1]}$. They can be a source of active components of biological and medicinal importance. They have traditionally occupied an important position in the socio-cultural, spiritual and medicinal arena of rural and tribal living in India ${ }^{[2]}$. Plants have been the sources of successful drugs from ancient times and will continuously be important for investigations of new medicinal compounds ${ }^{[3]}$.

\section{How to cite this article}

Hussain MA, Nathar VN. Phytochemical Profiling of Ruta graveolens L. a Vital Medicinal Plant Using Gas ChromatographyMass Spectrometry. SSR Inst. Int. J. Life Sci., 2020; 6(3): 2536-2543.

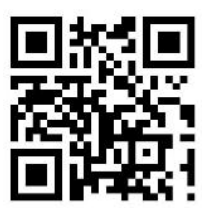

For proper standardization of herbals and its formulations the identification and quantification of active principal compounds is the need of the hour [4]. Thousands of these chemicals have been reported but still, there are many important components which have not been reported yet. Metabolic profiling has very wide range of applicability. Currently, the most effective technique for metabolic profiling is the use of Gas chromatography united with electron impact (EI) quadrupole or time of flight (TOF) mass spectroscopy (GC-MS). It has the capacity of identification and rapid quantification of few hundreds of metabolites within single extract ${ }^{[5]}$. Volatile compounds are directly separated and quantified by using Gas Chromatography and Mass Spectroscopy approach ${ }^{[6]}$. Another advantage of this technique is the rapid identification of metabolites using databases of mass spectra ${ }^{[7]}$. GC-MS studies have been used on a large scale for the analysis of medicinal plants as this technique has proved very 
useful for the investigation of several chemical compounds.

R. graveolens L. commonly known as Rue is a small evergreen sub-shrub or semi-woody perennial 0.6 to 0.9 $\mathrm{m}$ tall and almost as wide, originally native to the Mediterranean region. It belongs to Rutaceae family in the order of Sapindales that contains about 160 genera and more than 1600 species. Due to its cultural and medicinal value, rue has been introduced in various countries of North, Central and South America, China, India, Middle East and South Africa. The bioactive compounds of Ruta species are of great interest in medicinal chemistry, as they show a broad range of biological activity ${ }^{[8]}$. Hence the objective of the present study is to identify the phytochemical constituents in different extracts of $R$. graveolens with the aid of GC-MS technique.

\section{MATERIALS AND METHODS}

Plant material- The plants of $R$. graveolens L. were bought from Melghat region of Amravati District of Maharashtra State and were identified by Dr. S. R. Manik, Former Head Department of Botany, Sant Gadge Baba Amravati, University, Amravati, India.

Plant sample extraction- The collected $R$. graveolens leaves, stem and roots were air-dried at room temperature until constant weights and coarsely powdered with an electric grinder. Dried and powdered samples (3 gram each) were subjected to extraction with petroleum ether and chloroform separately for 24 hours using Soxhlet apparatus and concentrated using water bath. The extracts were then filtered through Whatman filter paper No. 42 to obtained the free and clear extract. This extract was then concentrated to $5 \mathrm{ml}$ and stored in refrigerator for further use.

\section{Gas Chromatography-Mass Spectrometry (GC-MS)} analysis- GC-MS analysis of the samples was carried out using Shimadzu Make QP-2010 with nonpolar 60 M RTX $5 \mathrm{MS}$ Column. Helium gas was used as a carrier gas and the temperature programming was set with initial oven temperature at $40 \circ \mathrm{C}$ and held for $3 \mathrm{~min}$ and the final temperature of the oven was $480^{\circ} \mathrm{C}$ with rate at 10 o $\mathrm{C} / \mathrm{min}$. Total $2 \mu \mathrm{L}$ sample was injected with splitless mode. Mass spectra was recorded over 35-650 amu range with electron impact ionization energy $70 \mathrm{eV}$. The total running time for a sample was $45 \mathrm{~min}^{[9]}$.
Identification of chemical constituents- The Interpretation of mass spectra obtained by the GC-MS method was conducted using the database of National Institute of Standards and Technology (NIST) having more than 62,000 patterns. The spectrums of the unknown components from the samples were compared with the spectrum of the known components stored in the NIST library. Name, molecular weight and structure of the components of the tested materials were ascertained.

\section{RESULTS}

In the present study, the in vivo plant samples (Leaves, Stem and Roots) were investigated for biologically active compounds by GC-MS analysis. The extracts showed the presence of many secondary metabolites belonging to different groups. It was observed that the $R$. graveolens L. on which scientific studies has been carried out are validated in their uses in various parts of the world. The GC-MS analysis revealed the presence of 1, 4 and 6 chemical compounds in chloroform extracts of leaves, stem and roots respectively. (Table 1, Fig. 1, 2 and 3). In chloroform extract of leaf only one compound Tricosane (RT 35.72) with $100 \%$ peak area was found whereas in stem extract the highest peak area $57.49 \%$ and the lowest peak area $2.34 \%$ in Chloroform extract was of Benzene, 1-(chloromethyl)-2-fluoro-(RT. 15.13) and phytol (RT. 28.16) respectively. The other compounds identified in stem extracts were 14.94\% Ethane hexachloro (RT. 11.50) and 25.22\% 1, 2Benzenedicarboxylic acid, diisononyl ester (RT. 23.90). Similarly in chloroform root extracts, the highest peak area (\%) of 52.86 and the lowest peak area (\%) of 2.50 was of Adamantane, 1,3-dichloro (RT 32.73) and Phosphonic acid, dioctadecyl ester (RT 30.48) respectively. The other compounds revealed in GC-MS analysis of Chloroform extract of roots were $6.17 \% 1$ Octadecanol (RT.29.69), 11.42\% 1-Bromodocosane (RT. 32.35), 16.03\% Cyclotetracosane (RT.33.14) and $11.03 \%$ Di-n-octyl phthalate (RT. 33.56). 
Table 1: GC-MS analysis of chloroform extracts of $R$. graveolens L.

\begin{tabular}{|c|c|c|c|c|c|c|}
\hline $\begin{array}{l}\text { Plant part } \\
\text { used }\end{array}$ & Peak No & RT & Name of Compounds & Peak area (\%) & MW & MF \\
\hline \multirow[t]{3}{*}{ Leaf } & 1 & 35.72 & Tricosane & 100 & 324 & $\mathrm{C}_{23} \mathrm{H}_{48}$ \\
\hline & 1 & 11.50 & Ethane, hexachloro & 14.94 & 234 & $\mathrm{C}_{2} \mathrm{Cl}_{6}$ \\
\hline & 2 & 15.13 & $\begin{array}{l}\text { Benzene, 1-(chloromethyl)-2- } \\
\text { fluoro }\end{array}$ & 57.49 & 144 & $\mathrm{C}_{7} \mathrm{H}_{6} \mathrm{ClF}$ \\
\hline \multirow{5}{*}{ Stem } & 3 & 23.90 & $\begin{array}{l}\text { 1,2-Benzenedicarboxylic acid, } \\
\text { diisononyl ester }\end{array}$ & 25.22 & 418 & $\mathrm{C}_{26} \mathrm{H}_{42} \mathrm{O}_{4}$ \\
\hline & 4 & 28.16 & Phytol & 2.34 & 296 & $\mathrm{C}_{20} \mathrm{H}_{40} \mathrm{O}$ \\
\hline & 1 & 29.69 & 1-Octadecanol & 6.17 & 270 & $\mathrm{C}_{18} \mathrm{H}_{38} \mathrm{O}$ \\
\hline & 2 & 30.48 & $\begin{array}{l}\text { Phosphonic acid, dioctadecyl } \\
\text { ester }\end{array}$ & 2.50 & 586 & $\mathrm{C}_{36} \mathrm{H}_{75} \mathrm{O}_{3} \mathrm{P}$ \\
\hline & 3 & 32.35 & 1-Bromodocosane & 11.42 & 388 & $\mathrm{C}_{22} \mathrm{H}_{45} \mathrm{Br}$ \\
\hline \multirow{3}{*}{ Root } & 4 & 32.73 & Adamantane, 1,3-dichloro & 52.86 & 204 & $\mathrm{C}_{10} \mathrm{H}_{14} \mathrm{Cl}_{2}$ \\
\hline & 5 & 33.14 & Cyclotetracosane & 16.03 & 336 & $\mathrm{C}_{24} \mathrm{H}_{48}$ \\
\hline & 6 & 33.56 & Di-n-octyl phthalate & 11.03 & 390 & $\mathrm{C}_{24} \mathrm{H}_{38} \mathrm{O}_{4}$ \\
\hline
\end{tabular}

RT= Retention time; $\mathrm{MW}=$ Molecular weight; $\mathrm{MF}=$ Molecular Formula

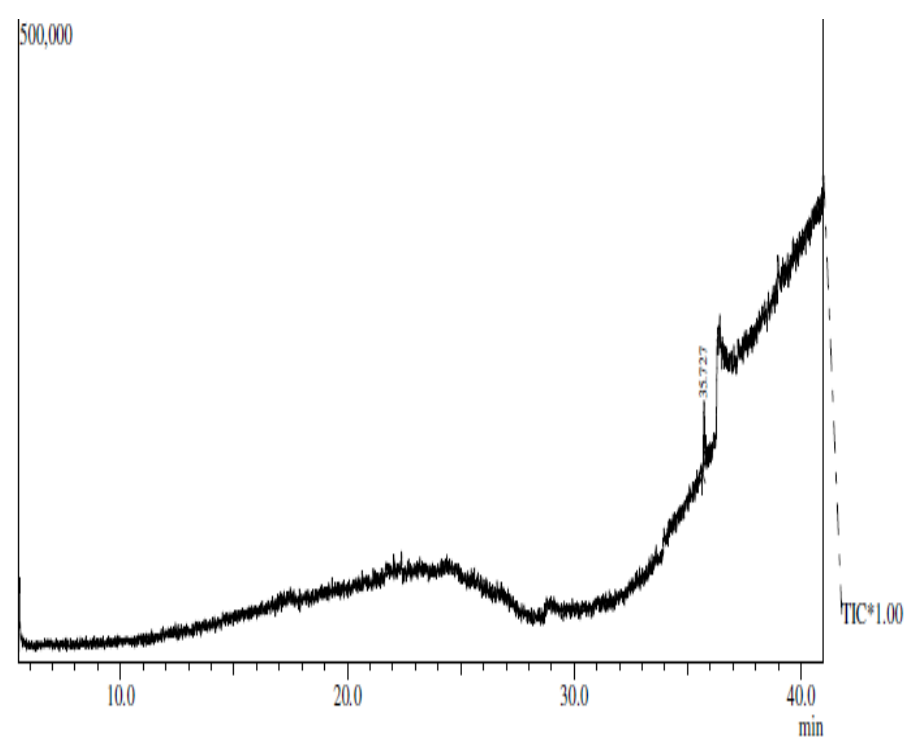

Fig. 1: GC-MS Chromatogram of Chloroform extract of Leaf of $R$. graveolens L.

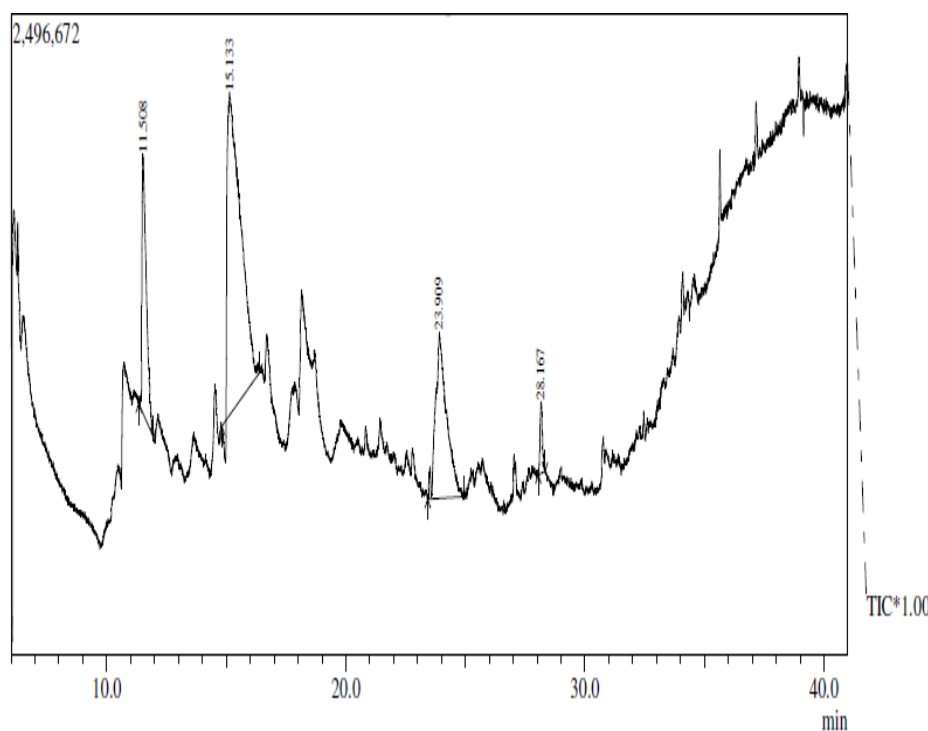

Fig. 2: GC-MS Chromatogram of Chloroform Extract of Stem of $R$. graveolens L. 


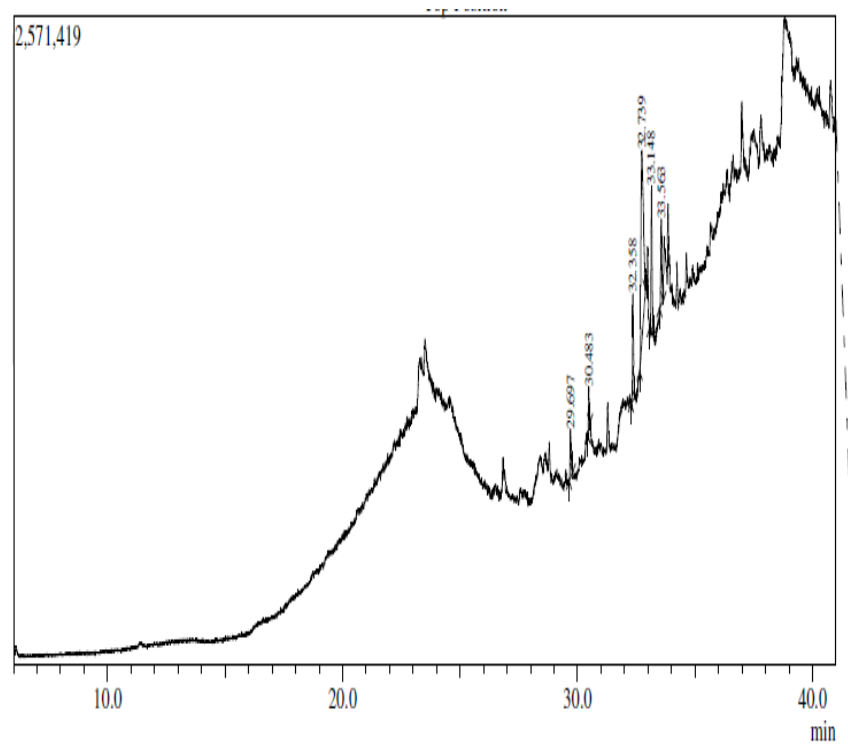

Fig. 3: GC-MS Chromatogram of Chloroform Extract of Root of $R$. graveolens $\mathrm{L}$.

The GC-MS analysis of petroleum ether extracts of leaves, stem and root extracts showed 1, 5 and 3 chemical constituents respectively (Table 2; Fig. 4, 5 and 6). which contribute to the pharmacological activity of the plant. The major compound found in leaf extract was Ergosta-5, 7-dien-3-ol, 3.beta. (Peak area 100\%). The highest peak area of $52.07 \%$ and the lowest peak area $1.62 \%$ in petroleum ether extract of the stem was of tetratriacontane (RT 35.89) and DOP; 1,2-

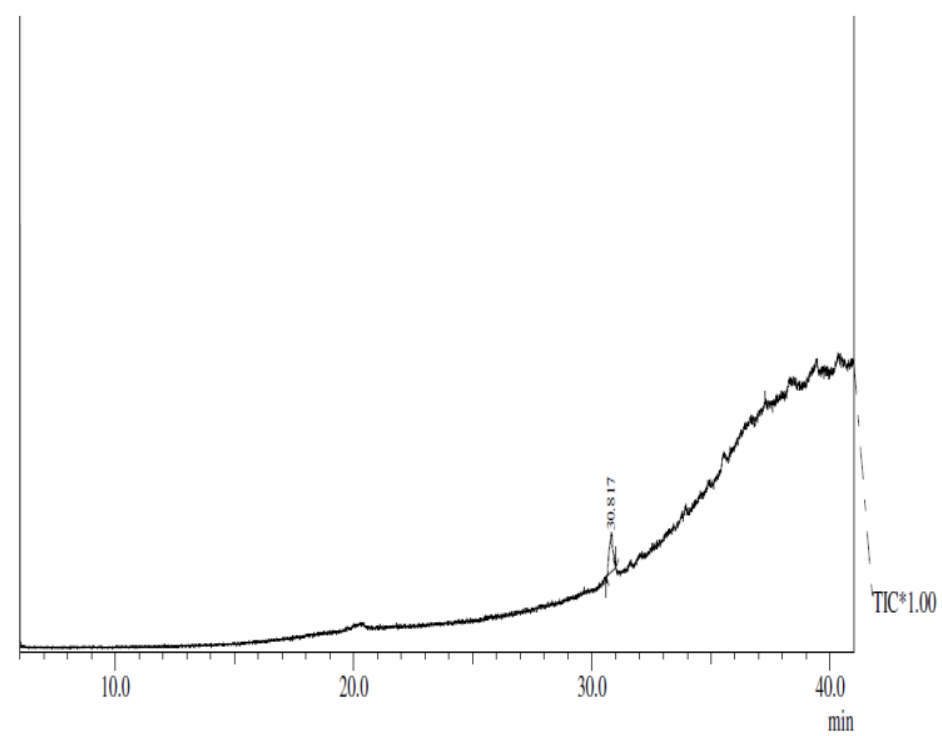

Fig. 4: GC-MS Chromatogram of Petroleum Ether Leaf Extract of $R$. graveolens $\mathrm{L}$.

Benzenedicarboxylic acid, bis(2-ethylhexyl) ester (RT 33.59) respectively. The other compounds identified were $36.53 \%$ Toluene (RT. 6.26), 7.96\% Eicosanoic acid (RT.23.14) and 1.82\% Octadecane (RT. 35.51). Similarly, the highest peak area $49.41 \%$ and the lowest peak area 24.05\% in Petroleum Ether extract of root was of 1,3,5Cycloheptatriene (RT 6.60) and Hexacosane (RT 30.95) respectively. The other compound identified was $26.53 \%$ Nonacosane (RT. 39.69).

Table 2: GC-MS Analysis of Petroleum ether Extracts of $R$. graveolens L.

\begin{tabular}{|c|c|c|c|c|c|c|}
\hline $\begin{array}{c}\text { Plant part } \\
\text { used }\end{array}$ & $\begin{array}{c}\text { Peak } \\
\text { No }\end{array}$ & RT & Name of Compounds & $\begin{array}{c}\text { Peak } \\
\text { area \% }\end{array}$ & MW & MF \\
\hline \multirow[t]{3}{*}{ Leaf } & 1 & 30.81 & Ergosta-5,7-dien-3-ol, (3.beta.)- & 100 & 398 & $\mathrm{C} 28 \mathrm{H} 46 \mathrm{O}$ \\
\hline & 1 & 6.26 & Toluene & 36.53 & 92 & $\mathrm{C} 7 \mathrm{H} 8$ \\
\hline & 2 & 23.14 & Eicosanoic acid & 7.96 & 312 & $\mathrm{C} 2 \mathrm{OH} 40 \mathrm{O} 2$ \\
\hline \multirow[t]{3}{*}{ Stem } & 3 & 33.59 & $\begin{array}{c}\text { DOP ; 1,2-Benzenedicarboxylic acid, } \\
\text { bis(2-ethylhexyl) ester }\end{array}$ & 1.62 & 390 & $\mathrm{C} 24 \mathrm{H} 38 \mathrm{O} 4$ \\
\hline & 4 & 35.51 & Octadecane & 1.82 & 254 & $\mathrm{C} 18 \mathrm{H} 38$ \\
\hline & 5 & 35.89 & Tetratriacontane & 52.07 & 478 & $\mathrm{C} 34 \mathrm{H} 70$ \\
\hline \multirow[t]{3}{*}{ Root } & 1 & 6.60 & 1,3,5-Cycloheptatriene & 49.41 & 92 & $\mathrm{C} 7 \mathrm{H} 8$ \\
\hline & 2 & 30.95 & Hexacosane & 24.05 & 366 & $\mathrm{C} 26 \mathrm{H} 54$ \\
\hline & 3 & 39.69 & Nonacosane & 26.53 & 408 & $\mathrm{C} 29 \mathrm{H} 60$ \\
\hline
\end{tabular}




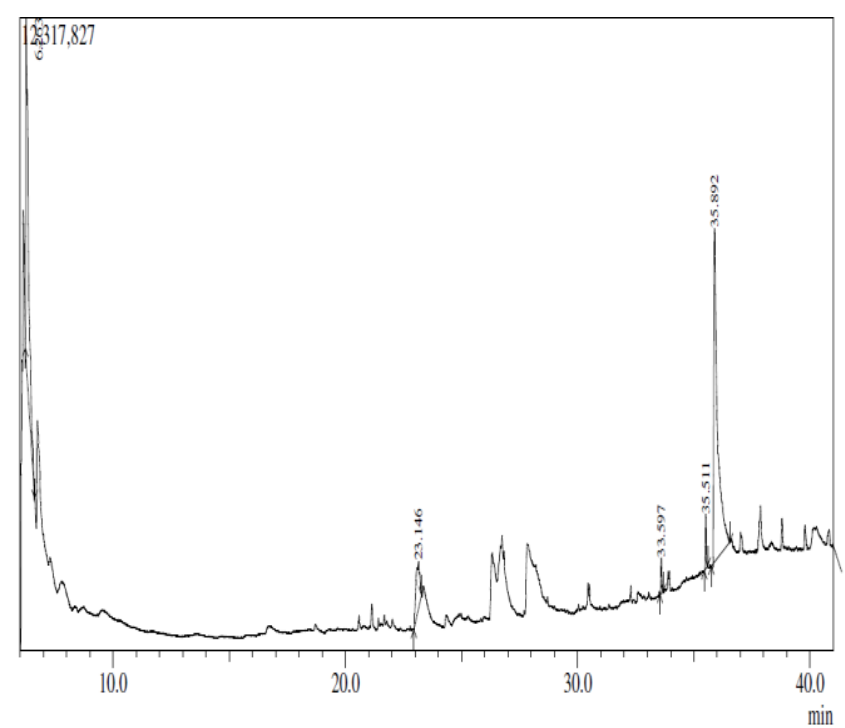

Fig. 5: GC-MS Chromatogram of petroleum ether Stem Extract of $R$. graveolens $L$.

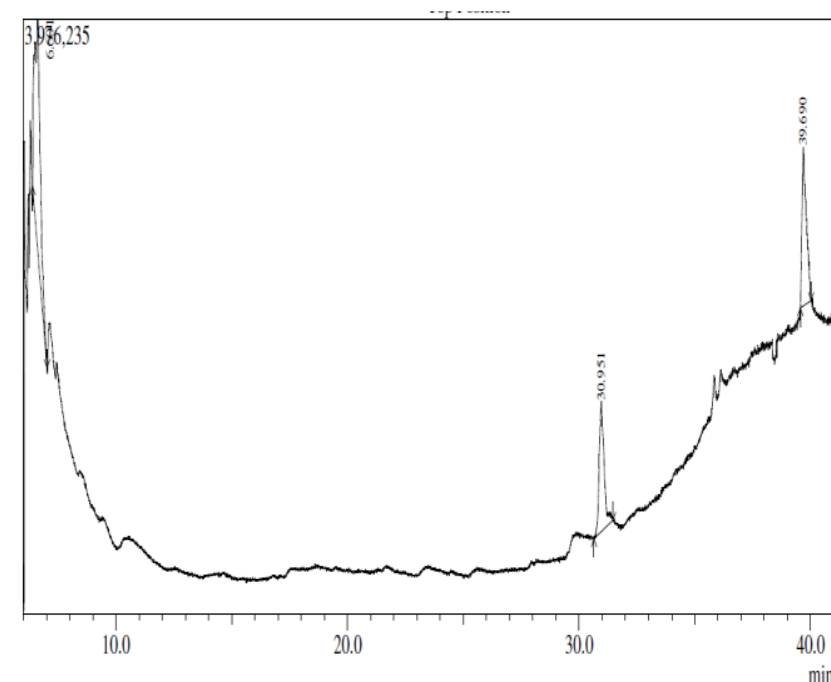

Fig. 6: GC-MS Chromatogram of Petroleum Ether Root Extract of $R$. graveolens $\mathrm{L}$.
WWMMM

Tricosane

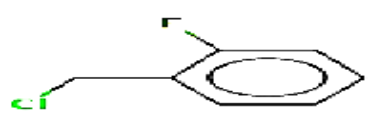

Benzene, 1-(chloromethyl)-2fluoro-

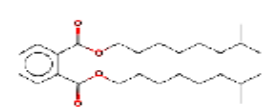

1, 2-Benzenedicarboxylic acid, diisononyl ester

\section{$M N N M N$}

1-Octadecanol

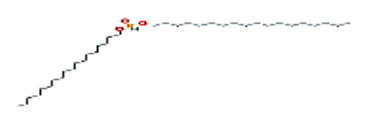

Phosphonic acid, dioctadecyl

$$
\text { Cl } \int_{c_{1}}^{c} c_{1}^{\prime}
$$

Ethane,hexacbloro
NNNNN

l-Bromodocosane

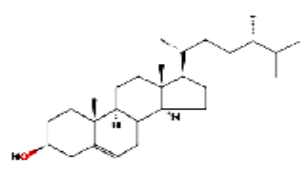

Ergosta-5,7-dien-3-ol, (3. beta.)-

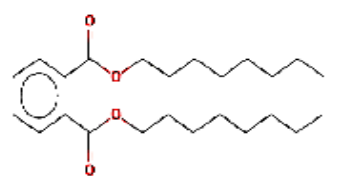

Di-n-octyl phthalate

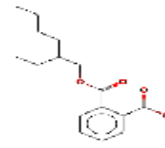

DOP ; 1,2-

Benzenedicarboxylic acid, bis(2-ethylhexyl) ester

\section{$M N M$}

Eicosanoic acid<smiles>Cc1ccccc1</smiles>

Toluene

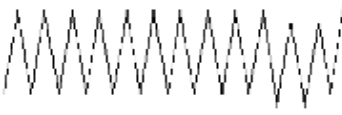

Hexacosane
1, 3, 5-Cycloheptatriene
Cyclotetracosane

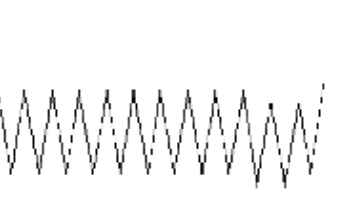

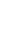




\section{DISCUSSION}

The members of Rutaceae family are used in medicine of which $R$. graveolens (Rue) is in the forefront and is native to Europe but not found all over the world ${ }^{[10]}$. Rue contains various active compounds belonging to the group flavonoids, coumarins, derivatives, furoquinolines, volatile oils etc ${ }^{[11]}$. Many of these compounds are yet to be identified. The recent scenario shows that there is again revival of interest in herbal medicines. The World Health Organisation has a strong thrust upon evaluation of these herbal drugs for some major diseases against modern drugs ${ }^{[12]}$. Hence, traditional and herbal medicine is the need of hour ${ }^{[13]}$. GC-MS analysis is an interesting technique to evaluate the large number of chemical constituents used in cosmetic, pharmaceutical and food industry ${ }^{[14]}$. The gas chromatogram shows the relative concentrations of various compounds getting eluted as a function of retention time. The heights of the peak indicate the relative concentrations of the components present in the plant. The mass spectrometer analyzes the compounds eluted at different times to identify the nature and structure of the compounds.

In the present study, the extraction of different plant parts was carried out to acquire the valuable information about secondary metabolites present in $R$. graveolens $\mathrm{L}$. The in vivo plant parts like leaves, stem and roots were investigated for biologically active compounds by GC-MS analysis which revealed the occurrences of 11 compounds in chlorofom extracts and 9 compounds in petroleum ether extracts. The screening of plants for medicinal value has been carried out by the number of researchers ${ }^{[15]}$. The presence of 79 metabolites from in vitro cultures of $R$. graveolens with a wide range of bioactivities like photobiological, anti-microbial, antioxidative ${ }^{[16]}$, anti-inflammatory ${ }^{[17]}$ among others with potential economic importance have been also reported ${ }^{[18]}$. Metabolite screening is very much important in identifying new source of therapeutically and industrially valuable compounds having medicinal importance, to make the best and judicious use of available natural resources. The selection of plant parts, which gives maximum number of bioactive compounds, was the important step in such investigations [19]. Several numbers of chemical constituents such as alkaloids, coumarins, terpenoids, steroids, flavonoids and furoquinolines have been isolated from different parts of the plant ${ }^{[20]}$. Besides these, several essential oils have been reported in $R$. graveolens having anti-inflammatory and cytotoxic properties ${ }^{[21]}$. The identification and isolation of these active compounds could lead to the new drug discovery at a cheaper cost which would be useful in medicine. The steroid Phytol from $R$. graveolens, was found to be cytotoxic against breast cancer cell lines (MCF7) ${ }^{[22,23]}$. R. graveolen possess diuretic, antimicrobial and anti-inflammatory activity ${ }^{[24]}$. The level of these metabolites in plants varies with the changing seasons, age and location ${ }^{[25]}$. The biological effects of furanocoumarins and furoquinolone alkaloids make them attractive for pharmaceutical uses; hence the considerable interest is shown in their availability and sources. In our earlier reports, we have reported the presence of 51 compounds in callus extracts of $R$. graveolens and 25 compounds in methanolic extracts of the same taxon with a wide range of bioactivities and potential economic importance [26,27]. Due to the presence of various secondary metabolites in the extracts, rue plant has the potential application in various pharmaceutical industries ${ }^{[28]}$.

\section{CONCLUSIONS}

In the present study, twenty chemical constituents have been identified from chloroform and petroleum ether extracts of leaves, stem and roots of the $R$. graveolens $\mathrm{L}$. by GC-MS analysis. The presence of these chemical constituents justifies the use of the plant for various diseases by traditional people. The study would lead to understanding the richness of bioactive components in different parts of $R$. graveolens $\mathrm{L}$. The present study would form a basis for understanding the richness of bioactive components in different extracts of $R$. graveolens L.

Further study should be carried out for large scale production and isolation of these compounds in pure form. The abundance of these components and their isolation would have potential applications in drug designing as well as in the medicine and healthcare industries.

\section{ACKNOWLEDGMENTS}

The authors express sincere thanks to Coordinator, Common Facility Center (CFC), Shivaji University, Kolhapur, Maharashtra, India for supporting instrumental analysis for this research work. 


\section{CONTRIBUTION OF AUTHORS}

Research concept- Dr. V. N. Nathar

Research design- Mr. Malik Aabid Hussain

Supervision- Dr. V. N. Nathar

Materials- Mr. Malik Aabid Hussain

Data collection- Dr. Malik Aabid Hussain

Data analysis and Interpretation- Mr. Malik Aabid Hussain

Literature search- Mr. Malik Aabid Hussain

Writing article- Mr. Malik Aabid Hussain

Critical review- Dr. V. N. Nathar

Article editing- Dr. V. N. Nathar

Final approval- Dr. V. N. Nathar

\section{REFERENCES}

[1] Bachrach ZY. Contribution of selected medicinal plants for cancer prevention and therapy.Acta Facultatis Medicae Naissensis, 2012; 29(3): 117-23.

[2] Kumar M., Sheikh M A, Bussmann RW. Ethnomedicinal and ecological status of plants in Garhwal Himalaya, India. J. Ethnobiol. Ethnomed., 2011; 7(1): 1-13.

[3] Atanasov AG, Waltenberger B, Pferschy-Wenzig EM, Linder $\mathrm{T}$, Wawrosch $\mathrm{C}$, et al. Discovery and resupply of pharmacologically active plant-derived natural products: a review. Biotechnol Adv., 2015; 3(8): 1582-614.

[4] Sharma P, Kaushik S, Jain A, Sikarwar SM. Preliminary phytochemical screening and HPTLC fingerprinting of Nicotiana tabacum leaf. J. Pharm. Res., 2010; 3(5): 1144-45.

[5] Fernie AR, Trethewey RN, Krotzky AJ, Willmitzer L. Metabolite profiling: from diagnostics to systems biology. Nature Rev. Mol. Cell Biol., 2004; 5(9): 763.

[6] Vladimir S. Metabolomics technology and bioinformatics. Briefings in bioinformatics, 2006; 7(2): 128-39.

[7] Maud MK, Renger HJ, Jan VG, Albert CT, Thomas H. Quantitative metabolomics based on gas chromatography mass spectrometry: status and perspectives. Metabolomics, 2011; 7(3): 307-28.

[8] Miguel ES. Rue in traditional Spain: frequency and distribution of its medicinal and symbolic applications. Econ. Bot., 2003; 57(2): 231-44.

[9] Patil A, Jadhov V. GC-MS analysis of bioactive components from methanol leaf extract of Toddaliaasiatica (L.). Int J Pharm Sci Rev Res., 2014; 29(1): 18-20.
[10]Raghav SK, Gupta B, Agrawal C, Goswami K, Das HR. Anti-inflammatory effect of Ruta graveolens L. in murine macrophage cells. J. Ethnopharmacol., 2006; 104(1-2): 234-39.

[11]Pathak S, Multani AS, Banerji P. Ruta 6 selectively induces cell death in brain cancer cells but proliferation in normal peripheral blood lymphocytes: A novel treatment for human brain cancer. Int. J. of oncol., 2003; 23(4): 975-82.

[12]Ayyanar M, Sankarasivaraman K, Ignacimuthu S. Traditional herbal medicines used for the treatment of diabetes among two major tribal groups in south Tamil Nadu, India. Ethnobotanical Leaflets, 2008; 12: 276-80.

[13]Arulrayan N, Rangasamy S, James E, Pitchai D. A database for medicinal plants used in the treatment of diabetes and its secondary complications. Bioinformation, 2007; 2(1): 22-23.

[14] Gomathi D, Kalaiselvi M, Ravikumar G, Devaki K, Uma C. GC-MS analysis of bioactive compounds from the whole plant ethanolic extract of Evolvulus alsinoides (L.) L. J. Food Sci. Technol., 2015; 52(2): 1212-17.

[15]Ram RL. Preliminary phytochemical analysis of medicinal plants of South Chotanagpur used against dysentery. Adv. Plant Sci., 2001; 14: 525-30.

[16]Kim YS, Yeung EC, Hahn EJ, Paek KY. Combined effects of phytohormone, indole-3-butyric acid, and methyl jasmonate on root growth and ginsenoside production in adventitious root cultures of Panax ginseng CA Meyer. Biotechnol. Lett., 2007; 29(11): 1789-92.

[17]Harris C, Henttu P, Parker M, Sumpter J. The estrogenic activity of phthalate esters in vitro. Environ. Health Perspect., 1997;105: 802-811.

[18]Diwan R, Malpathak N. Ruta graveolens cultures as screening resources for phyto-pharmaceuticals: bioprospecting, metabolic phenotyping and multivariate analysis. Jaime A. Teixeira da Silva, Bioremediation (eds) Biodiversity and bioavailability. Global Science Books, 2011; 5: 1-9.

[19]Kokate CK, Purohit AP, Gokhale SB. Practical pharmacogonosy, $1^{\text {st }}$ ed., Vallabh prakashan Delhi; 1998.

[20]Kuzovkina I, Al-terman I, Schneider B. Specific accumulation and revised structures of acridone alkaloid glucosides in the tips of transformed roots of Ruta graveolens. Phytochem., 2004; 65: 1095-100. 
[21]Ratheesh M, Shyni GL, Sindhu G, Helen A. Inhibitory effect of Ruta graveolens L. on oxidative damage, inflammation and aortic pathology in hypercholesteromic rats. Exp. Toxicol. Pathol., 2011; 63: 285-90.

[22]Ogunlesi M, Okiei W, Ofor E, Osibote AE. Analysis of the essential oil from the dried leaves of Euphorbia hirta Linn (Euphorbiaceae), a potential medication for asthma. Afr. J. Biotechnol., 2009; 8(24):7042-50.

[23]Satyal P, Dosoky NS, Poudel A, Setzer WN. Essential oil constituents and their biological activities from the leaves of Cassia fistula growing in Nepal. J. Medicinal and Aromatic Plants, 2012; 3(2): 1.

[24]Jananie RK, Priya V, Vijayalakshmi K. Determination of bioactive components of Cynodon dactylon by GCMS analysis. NY Sci. J., 2011; 4(4): 1-5.
[25]Hamburger MO, Cordell GA, Ruangrungsi $\mathrm{N}$. Traditional medicinal plants of Thailand XVII Biologically active constituents of Plumeria rubra. J. Ethnopharmacol., 1991; 33(3): 289-92.

[26] Malik AH, Varsha NN, Javid IM. Gas ChromatographyMass Spectrometry (GC-MS) analysis in callus extracts of Ruta graveolens L. World J. Pharm. Res., 2017a; 6(12): 1195-210.

[27]Malik AH, Varsha NN, Javid IM. GC-MS Analysis of Methanolic extracts of Ruta graveolens L. for Bioactive Compounds. Am. J. Pharmatech Res., 2017b; 7(2): 315-24.

[28]Mancuso G, Borgonovo G, Scaglioni L, Bassoli A. Phytochemicals from rue activate TAS2R bitter taste receptors and TRP channels involved in gustation and nociception. Mol., 2015; 20: 18907-22. 